\title{
Performance Evaluation of Reclaimed Asphalt Pavements
}

\author{
Asif Nawaz ${ }^{1}$, Fazle Karim ${ }^{2}$, Khalid Mahmood ${ }^{3}$, Sher Afzal Khan ${ }^{4}$ \\ ${ }^{1,2,3,4}$ Sarhad University of Science \& Information Technology, Peshawar \\ asifnawaz739@gmail.com ${ }^{1}$, engr_fazli@yahoo.com ${ }^{2}$, khalid.civil@ suit.edu.pk ${ }^{3}$, hod.civil@ suit.edu.pk ${ }^{4}$ \\ Received: 15 November, Revised: 20 November, Accepted: 22 November
}

\begin{abstract}
The extensive use of organic and virgin aggregates contributes to their resource exploitation. High priority must be given to the partial substitution of conventional aggregates with recyclable construction material, which must be environmentally responsible and should function equally too as the conventional material. Reclaimed Asphalt Pavements (RAP) is a great choice for the asphaltic wearing and asphaltic base courses of road pavements. In this research, the properties were determined for various combinations and proportions of virgin and aged asphalts.
\end{abstract}

In this study, six blends which were the mixtures of virgin materials and RAP, were analyzed. The blends were designed with a wide variety of RAP blends from 0 to 100 percent by Marshall Method of design. The rutting performance of the blends was also determined in-order to check the deformation. The RAP content was combined with virgin aggregates in such a way that all the test samples had about the same gradation. RAP-containing mixtures showed significant variation and the properties indicated improvement with the increase in RAP material. The results show that up to 40 percent of RAP material can be used efficiently in the construction of wearing courses.

Keywords - RAP, Hot Mix Asphalt, Marshal Mix Design, Rutting performance, Recycling.

Abbreviations:

RAP------------Reclaimed Asphalt Pavement

HMA----------Hot Mix Asphalt

OBC-----------Optimim Binder Content

NHA-----------National Highway Authority

Va---------------Air voids

VMA----------Voids in mineral aggregates

VFA-----------Voids filled with aggregates

NMAS--------Nominal Maximum Aggregate Size

\section{INTRODUCTION}

\section{A. General:}

Expansion, rehabilitation, and maintenance of any transportation system depend on fiscal resources to finance the system; the technology to plan, design, construct, and maintain the facility in an economic manner; supplies of aggregate and binder; and equipment and manpower resources with which to construct and maintain the facilities. Transportation facilities controlled by federal, state, and local agencies are faced with several problems, including:

- Decrease in assets that are available for transportation potentials, has given rise due to these circumstances has resulted in a decrease in assessment base, inflation, a decrease in revenue from fuel costs and also in monetary demands for further projects.

- Resource supply issues arising from the use of sources close to the purpose of utilization; increased separate pull and associated transport costs; strictures forced by zoning laws; strong ecological codes restricting the production in specific regions and requiring substantial uses for the protection of pit and quarry reconstruction, for the quality of air and water, and for the reduction of noise; and the use of asphalt materials for different purposes.

- Issues of accessibility that regards with the equipments coming about as a result of diminished budgets, various components and the new gear's high cost.

- Work related issues arise due to because of financial wage constraints on wages that often contributes to the absence of prepared equipment administrators and eligible buildingfocused officials; work organization problems; \& the need to extend the value of efficient operation.

- Vitality issues related to the availability of fuel, as well as the cost and urgent need to reduce the use of fuel.

Because of the problems discussed above, there is a pressing need to improve the use of binders, aggregates, manpower, equipment and energy, funds from planning, design, construction, rehabilitation, and maintenance standpoints. 


\section{Asphalt:}

Asphalt is not only a strong, climate-resistant, chemicalresistant and flexible binding material but it also adapts to a number of uses, most commonly for the purpose of binding crushed stone with aggregate in to a hard, tough surface for roads, streets and airport taxiways or runways.

Within the processing method of crude oil, the primary supplies of asphalt can be found. The ever-changing characteristics (physical and chemical) are primarily due to the natural changes in crude oil sources or refining practices, thereby affecting residual asphalt quality on the road.

Hot asphalt concrete mixture (HMAC) consists of:

- Aggregates

- Asphalt binder

- $\quad$ Mineral Filler

\section{Reclaimed Asphalt Pavement:}

Milled materials are still importance, even if hot mix asphalt (HMA) reaches the end of its useful life. These Milled Materials can be reused and lessen the quantity of new material if combined with virgin HMA which furthermore degrades the new bitumen's quantity required in the production of Hot Mix Asphalt (HMA) and thereby the cost decreases and preserve natural resources [1].

\section{B. Historical Background:}

During the last several years in United States, hot mix asphalt processing has been used comprehensively. As Reclaimed Asphalt Pavements (RAP) typically have performed the same or better than the new HMA pavements, it is no longer considered as an experimental program. Consequently, much less research programs are assessing the relative performance of reclaimed and virgin hot mix asphalt pavements.

In Florida, recycled HMA is being used since 1978. Reports shows that pavements constructed by milling or replacement by reclaimed HMA performs better than those constructed of virgin overlay and wearing courses. By full-depth milling of cracked layers, various reflective cracks have been removed successfully. Compared to virgin HMA, the laboratory and inplace analysis of reclaimed HMA showed similar or better results [4].

In an evaluation study in Georgia comprised of the performance of evaluation of reused \& conventional hot mix asphalt surface layers in five projects. The content of 'Reclaimed Asphalt Pavements' (RAP) in these mixtures was from $10 \%$ to $40 \%$. The results of both conventional \& the reclaimed portions were described to be conducting acceptably having no notable rutting, weathering and raveling, and fatigue crackings. The average rut depth of the reclaimed sections was $2 \mathrm{~mm}(0.08 \mathrm{in}$.), with no fatigue cracking or raveling, and a very less longitudinal and transverse cracking. A quantitative analysis found no noticeable difference in in-service HMA mix and reclaimed asphalt cement properties and quality of recycled and virgin HMA test portions in these 5 projects [2].

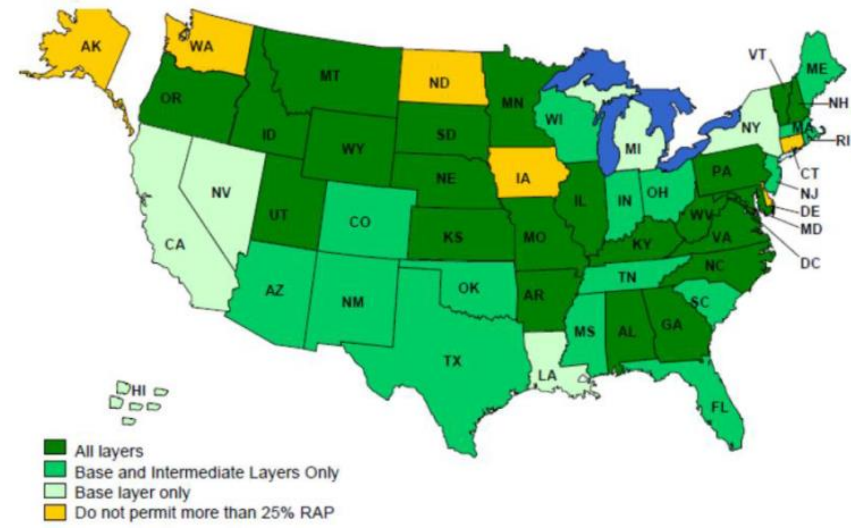

Fig 1: The states that use various \%ages of rap in HMA mixtures [1]

From 1987 to 1992, eight warm in-place recycled programs were accomplished in New York. All these projects were satisfactorily accomplished in 1992. Of the eight projects, six had average daily traffic volumes ranging from 9000 to 62000 vehicles on interstates [5].

The objectives of this study are:

1) To find out the best compatible amount of RAP with new pavement materials to withstand the traffic and climate loads in Pakistan.

2) To minimize the cost of new materials required for construction of pavement.

\section{METHODOLOGY}

The methodology acquired to attain the objectives of this research that includes collection of materials, testing of materials, sample's preparation and different tests on specimens. The study was carried out under controlled conditions. The determination of OBC was determined at varying percentages of asphalt (3\% to 5\%) using Marshal Mix Design. Based on the OBC results, performance testing was done. Performance testing includes Marshal Mix design and Rutting performance test at various percentages of reclaimed asphalt pavements (RAP).

\section{A. Material Collection}

For this research new aggregates were obtained from Margalla hills crush plant site which is observed to be the vast live aggregate quarry in Pakistan and bitumen binder of penetration grade $60 / 70$ that is usually being used in many of the highway projects was collected from Attock Refinery Limited.

The RAP material was collected in the form of pieces from Naguman located on main charsadda road leading to Peshawar. To meet the specified grading needs, the RAP pieces were crushed $\&$ broken to various sizes. Prior to bitumen extraction, the particles of size $25 \mathrm{~mm}$ were eliminated as the standard NMAS was $19 \mathrm{~mm}$.

\section{B. GRADATION SELECTION}

"Gradation is perhaps the aggregate's most important property. It affects nearly all of the major properties of HMA 
which includes permeability, stability, stiffness, workability, durability, frictional resistance, fatigue resistance and moisture resistance." [3]. In this research, NHA Class A wearing course and gradation was used, which is further discussed in this chapter. Wearing course samples is of 4-inch diameter, for the Marshall method were prepared.

Table 1: NHA Class 'A' Wearing Course Aggregate Gradation

\begin{tabular}{|c|c|c|c|}
\hline \multicolumn{2}{|c|}{ Sieve Size } & $\begin{array}{c}\text { \% Commulative } \\
\text { Passing }\end{array}$ & \% Passing (AVG) \\
\hline (mm) & (inch) & & \\
\hline 25 & 1 & 100 & 100 \\
\hline 19 & $3 / 4$ & $90-100$ & 95 \\
\hline 9.5 & $3 / 8$ & $50-70$ & 63 \\
\hline 4.75 & $\# 4$ & $35-50$ & 42.5 \\
\hline 2.38 & $\# 8$ & $23-35$ & 29 \\
\hline 1.18 & $\# 16$ & $5-12$ & 8.5 \\
\hline 0.075 & $\# 200$ & $2-8$ & 5 \\
\hline Pan & & & \\
\hline
\end{tabular}

The extraction of Asphalt test was performed using AASTHO T 164, "the quantitative extraction of bitumen out of paving mixtures", to determine the $\%$ of asphalt binder in RAP material. The gradation of RAP source and the binder content of the source after extraction and are listed in (Table 3.2). All these tests were performed in duplicate \& the values that are mentioned are the average values.

Virgin and RAP source was used in various proportions ( 0 , $20 \%, 40 \%, 60 \%, 80 \%$, and $100 \%$ RAP). For this work, laboratory testing was restricted to $19 \mathrm{~mm}$ nominal total aggregate size (NMAS). The Marshall Mix design technique was adopted for the design of wearing section mixture and further rutting test was performed in order to check the deformation.

Table 2: Gradation of RAP Source

\begin{tabular}{|c|c|c|}
\hline \multicolumn{2}{|c|}{ Bitumen Content (\%) } & 3.3 \\
\hline \multicolumn{2}{|c|}{ Sieve Size } & $\begin{array}{c}\text { \% } \\
\text { Passing } \\
\text { (Avg) }\end{array}$ \\
\hline (mm) & (inch) & 100 \\
\hline 25 & 1 & 93 \\
\hline 19 & $3 / 4$ & 66 \\
\hline 9.5 & $3 / 8$ & 40 \\
\hline 4.75 & $\# 4$ & 32 \\
\hline 2.38 & $\# 8$ & 9 \\
\hline 1.18 & $\# 16$ & 6 \\
\hline 0.075 & $\# 200$ & \\
\hline pan & & \\
\hline
\end{tabular}

According to AASHTO T 166, water absorption and bulk specific gravity of the Marshall mixes were calculated. The flow and stability tests were performed in conjunction with AASHTO T 245 after assessing the bulk specific gravity of the test samples. For both marshal testing and rutting performance testing based on 4 percent air void, the optimum asphalt content was 4.2 percent for control mix. The maximum amount of asphalt in the mixture was estimated to be equal to the mixtures of 100 percent virgin wearing course mixtures.

\section{Calculation of Percentage of New Bitumen Required:}

The new bitumen binder percentage was determined using the equation shown below for the 10 to 80 percent RAP mixtures. The 100 percent RAP mixture samples were compacted without the addition of new binder as the RAP binder then exceeds the optimum asphalt content.

\% New Asphalt, $=P n b=\left\{\left(100^{2}-r P s b\right) P b /\right.$ $100(100-P s b)\}-\{(100-r) P s b /(100-P s b)\}---$ $--------($ Asphalt Institute, 1986$)$

Where,

$\mathrm{Pb}=$ Asphalt content of recycled mix, \%

$\mathrm{Pnb}=$ Amount of additional asphalt \&/or recycling agent in reclaimed mix, percent

$\mathrm{R}=$ Percent New asphalt \&/or recycling agent in recycled mix to total asphalt

\section{Marshal Stability and Flow Test:}

The Marshall flow \& stability test for the Marshall mix design method provides the performance prediction determination. The test's stability section measures the specimen's maximum load at a loading rate of $50.8 \mathrm{~mm} / \mathrm{min}(2$ $\mathrm{in} / \mathrm{min}$ ). Primarily, the load is increased up to it reaches a peak, then the load is stopped and the maximum load is recorded when the load just starts to decrease.

As a result of the loading, a dial gauge attached tests the plastic flow of the sample. The flow value is measured increments of $0.25 \mathrm{~mm}(0.01$ in) concurrently with the measurement of the maximum load.

Table 3: Typical Marshal Mix Design Stability and Flow criteria

\begin{tabular}{|c|c|c|c|c|c|c|}
\hline \multirow[t]{2}{*}{ Mix Criteria } & \multicolumn{2}{|c|}{$\begin{array}{l}\text { Light Traffic } \\
\text { (less than } \\
\text { 104ESALs) }\end{array}$} & \multicolumn{2}{|c|}{$\begin{array}{c}\text { Medium } \\
\text { Traffic (104 - } \\
\text { 106ESALs) }\end{array}$} & \multicolumn{2}{|c|}{$\begin{array}{c}\text { Heavy } \\
\text { Traffic } \\
\text { (greater than } \\
\text { 106ESALs) }\end{array}$} \\
\hline & Min. & Max. & Min. & Max. & Min. & Max. \\
\hline $\begin{array}{l}\text { Compaction } \\
\text { (number of } \\
\text { blows on each } \\
\text { end of the } \\
\text { sample) }\end{array}$ & \multicolumn{2}{|c|}{35} & \multicolumn{2}{|c|}{50} & \multicolumn{2}{|c|}{75} \\
\hline $\begin{array}{c}\text { Stability } \\
\text { (minimum) }\end{array}$ & \multicolumn{2}{|c|}{$\begin{array}{c}2224 \text { N (500 } \\
\text { lbs.) }\end{array}$} & \multicolumn{2}{|c|}{$\begin{array}{c}3336 \text { N (750 } \\
\text { lbs.) }\end{array}$} & \multicolumn{2}{|c|}{$\begin{array}{c}6672 \mathrm{~N}(1500 \\
\text { lbs.) }\end{array}$} \\
\hline $\begin{array}{c}\text { Flow }(0.25 \\
\text { mm }(0.01 \\
\text { inch }))\end{array}$ & \multicolumn{2}{|c|}{ 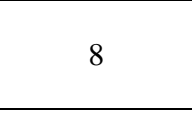 } & \multicolumn{2}{|c|}{20} & \multicolumn{2}{|c|}{8} \\
\hline $\begin{array}{l}\text { Percent Air } \\
\text { Voids }\end{array}$ & \multicolumn{2}{|c|}{3} & \multicolumn{2}{|c|}{5} & \multicolumn{2}{|c|}{5} \\
\hline
\end{tabular}

\section{RESULTS AND DISCUSSIONS}

The Marshall Mix design of conventional mix i-e (virgin aggregates from Margalla Hills and Attock Refinery bitumen of penetration grade 60/70) and of RAP source with Margalla 
aggregates are summarized in Table 4 and 5 as shown. All the mixtures containing RAP, satisfy the minimum stability criteria of $6 \mathrm{KN}$ for heavy traffic and also fulfill the VMA and VFA specifications, but the flow values of the last three samples of RAP, two of which $(80 \% \& 100 \%$ RAP) failed to meet the maximum specification criteria i.e. $16(0.25 \mathrm{~mm}(0.01 \mathrm{in}))$ and the samples containing 60\% RAP nearly satisfies the maximum flow criteria. The rutting performance of the mixtures (shown in Table 6) also satisfied the rut depth specifications criteria up to $40 \%$ of RAP, the mixtures containing amount of RAP above $40 \%$ failed to satisfy the maximum rut depth criteria. Generally the properties of the mixtures improve with the By RAP material; the properties of the mixtures generally improve which shows that recycling is a viable option for HMA design. The variability in the properties of the mixtures is due to the variability of the RAP material that generally increases with the increase in percentages of RAP.

Table 4: Marshal Parameters Determined For Conventional Mix

\begin{tabular}{|c|c|c|c|c|c|c|c|}
\hline $\begin{array}{c}\text { Bitu } \\
\text { men } \\
\%\end{array}$ & $\begin{array}{c}\text { Va } \\
(\%)\end{array}$ & $\begin{array}{c}\text { VMA } \\
(\%)\end{array}$ & $\begin{array}{c}\text { VFA } \\
(\%)\end{array}$ & Gmb & Gmm & $\begin{array}{c}\text { Stabi } \\
\mathbf{( K N y}\end{array}$ & $\begin{array}{c}\text { Flow } \\
\mathbf{( \mathbf { 0 . 2 5 }} \\
\mathbf{m m} \\
\mathbf{( 0 . 0 1 i} \\
\mathbf{n}) \mathbf{~}\end{array}$ \\
\hline 3.5 & 5.54 & 14.12 & 53.65 & 2.334 & 2.500 & 10.12 & 12 \\
\hline 4 & 4.25 & 13.69 & 63.82 & 2.361 & 2.484 & 11.50 & 11.87 \\
\hline 4.5 & 3.35 & 13.45 & 72.85 & 2.378 & 2.468 & 12.87 & 11.53 \\
\hline 5 & 3.00 & 14.02 & 78.15 & 2.375 & 2.451 & 11.95 & 11.7 \\
\hline 5.5 & 2.82 & 14.56 & 80.26 & 2.372 & 2.443 & 10.56 & 11.9 \\
\hline
\end{tabular}

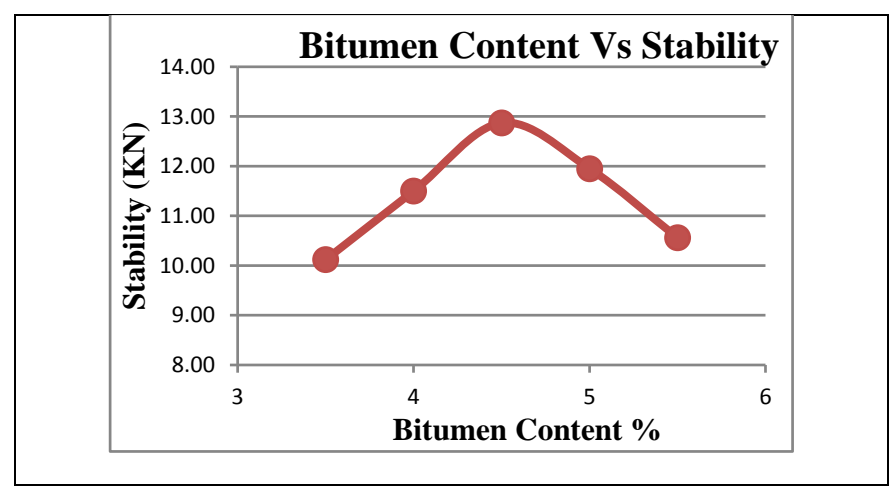

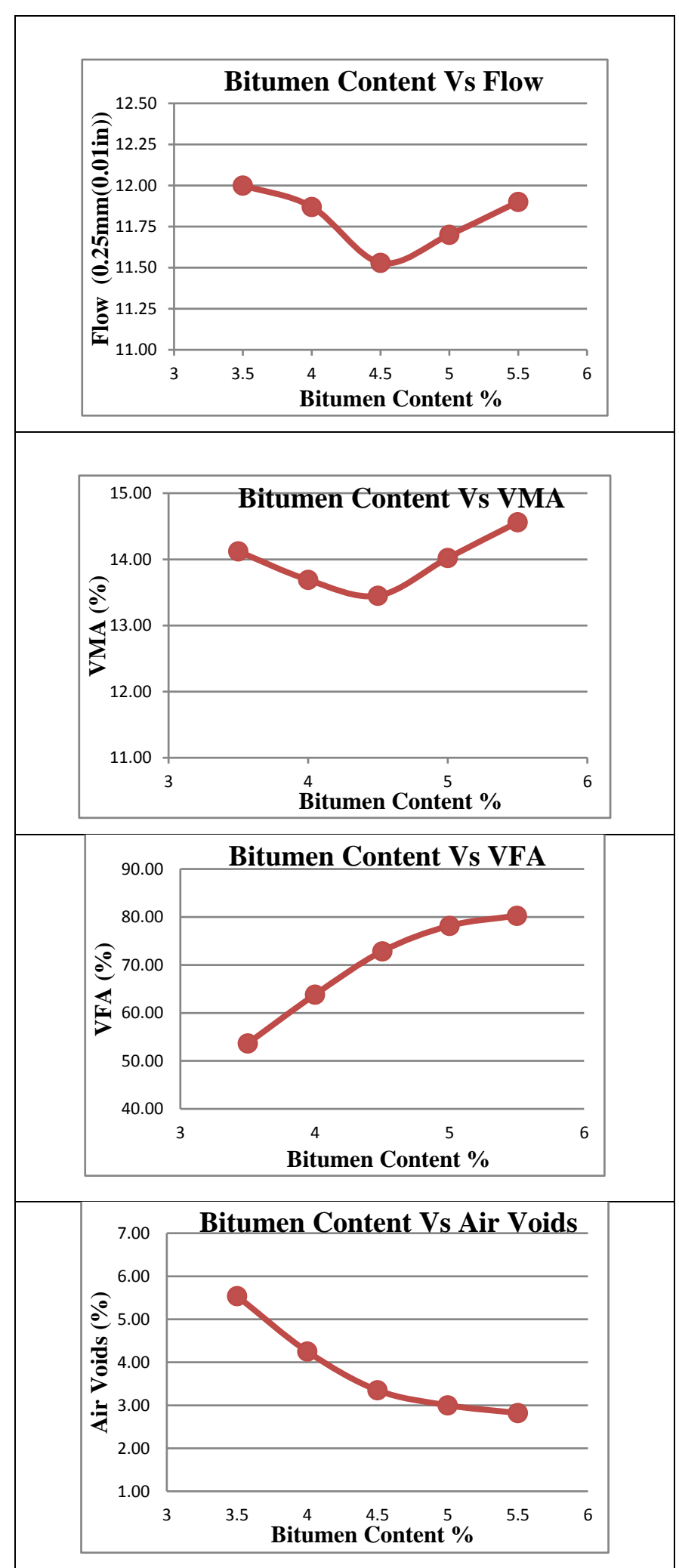




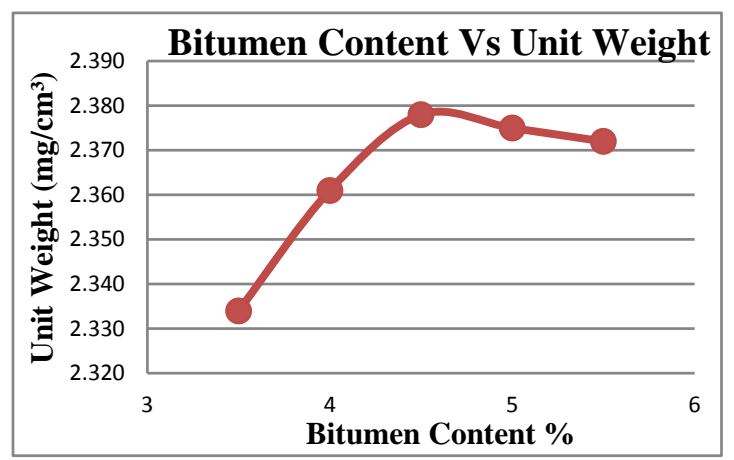

Figure 2: Plots of Bitumen Content Vs Volumetrics

Table 5: Marshal Parameters Determined for RAP Mix

\begin{tabular}{|l|c|c|c|c|c|c|c|}
\hline $\begin{array}{c}\text { RAP } \\
\%\end{array}$ & $\begin{array}{c}\text { Va } \\
\%\end{array}$ & $\begin{array}{c}\text { VMA } \\
\%\end{array}$ & $\begin{array}{c}\text { VFA } \\
\%\end{array}$ & Gmm & Gmb & $\begin{array}{c}\text { Stabili } \\
\text { ty } \\
(\mathbf{K N})\end{array}$ & $\begin{array}{c}\text { Flow(0 } \\
\mathbf{. 2 5 m m} \\
(\mathbf{0 . 0 1 i n} \\
))\end{array}$ \\
\hline $0 \%$ & 4.0 & 13.25 & $\begin{array}{c}70.5 \\
0\end{array}$ & $\begin{array}{c}2.36 \\
5\end{array}$ & $\begin{array}{c}2.53 \\
0\end{array}$ & 11.50 & 11.50 \\
\hline $20 \%$ & 3.87 & 13.95 & $\begin{array}{c}74.5 \\
6\end{array}$ & $\begin{array}{c}2.37 \\
9\end{array}$ & $\begin{array}{c}2.47 \\
0\end{array}$ & 10.50 & 10.50 \\
\hline $40 \%$ & 3.80 & 14.00 & $\begin{array}{c}77.9 \\
7\end{array}$ & $\begin{array}{c}2.39 \\
1\end{array}$ & $\begin{array}{c}2.41 \\
0\end{array}$ & 09.77 & 09.77 \\
\hline $60 \%$ & 3.00 & 12.80 & $\begin{array}{c}82.2 \\
1\end{array}$ & $\begin{array}{c}2.38 \\
7\end{array}$ & $\begin{array}{c}2.36 \\
0\end{array}$ & 12.97 & 12.97 \\
\hline $80 \%$ & 2.69 & 12.25 & 84.5 & 2.38 & 2.28 & 16.11 & 16.11 \\
& & & 1 & 4 & 0 & & \\
\hline 100 & 2.42 & 11.55 & 86.5 & 2.38 & 2.20 & 17.12 & 17.12 \\
$\%$ & & & 5 & 0 & 0 & & \\
\hline
\end{tabular}

The plots below indicates that using RAP content up to 40 percent is acceptable as the stability increases because of the mixture containing aggregates from two sources(i.e virgin and RAP source) and also the RAP material comprises of the thin bitumen film coating which makes the mix more stable but above 40 percent the flow is exceeding the maximum flow requirement of Marshal Mix Design, as the amount of bitumen increases so as the flow also increases which makes the mix susceptible to rutting.
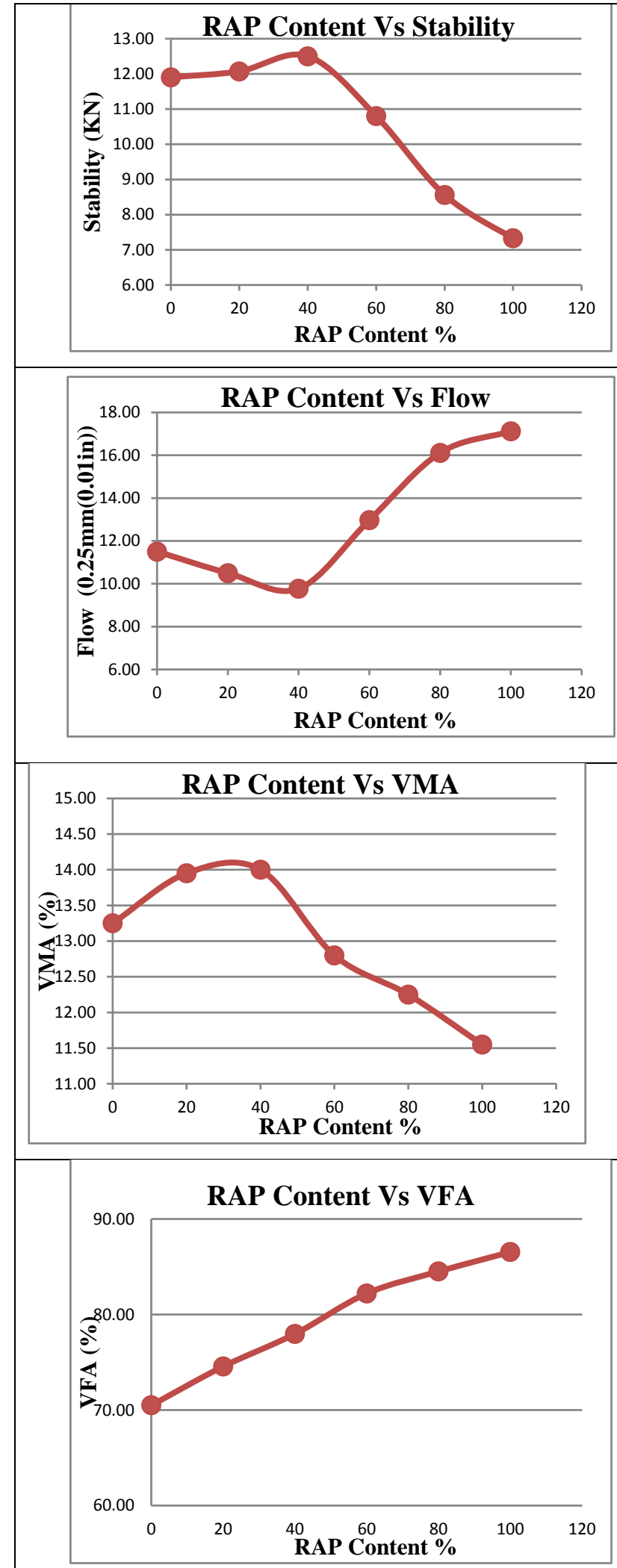


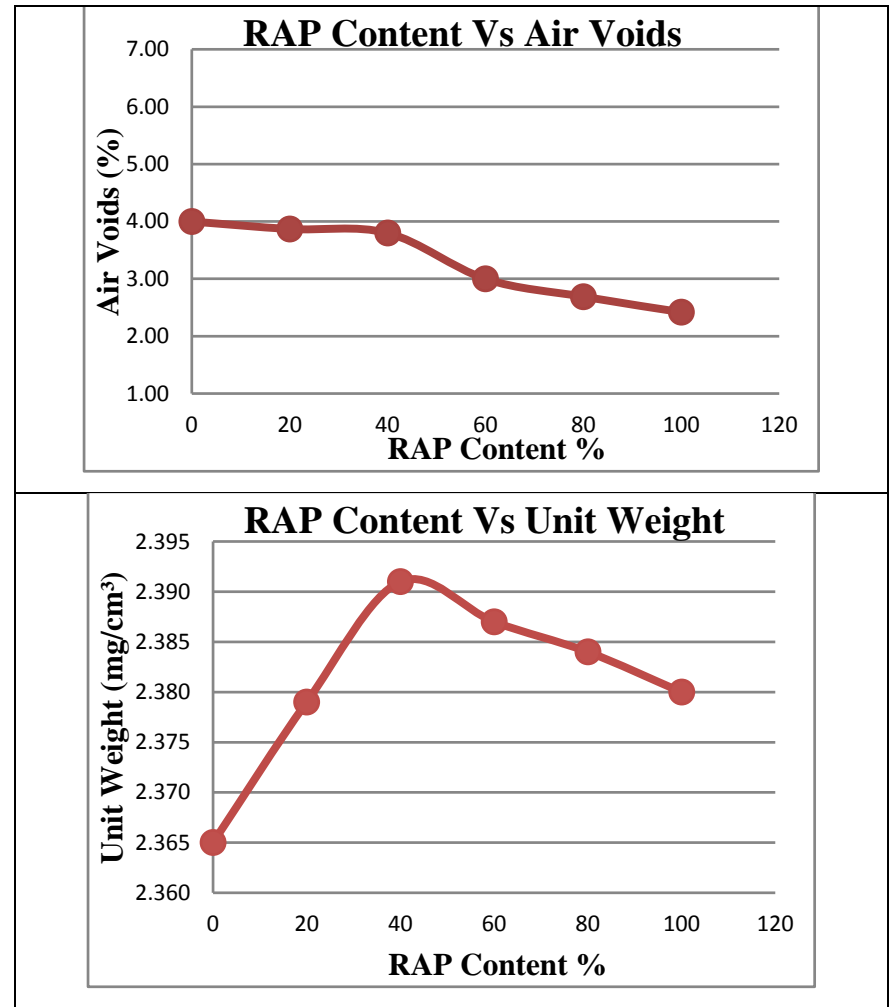

Figure 3: Plots of RAP Contents VS Volumetrics

Table 6: Summary of Rutting Performance of Mixtures

\begin{tabular}{|c|c|}
\hline \multicolumn{2}{|c|}{$\begin{array}{c}\text { Pass Criteria: Maximum 12mm Rutting depth at 10000 } \\
\text { Passes }\end{array}$} \\
\hline RAP\% & Rut Depth(mm) \\
\hline $0 \%$ & 8.51 \\
\hline $20 \%$ & 7.61 \\
\hline $40 \%$ & 4.18 \\
\hline $60 \%$ & 11.97 \\
\hline $80 \%$ & 13.21 \\
\hline $100 \%$ & 15.21 \\
\hline
\end{tabular}

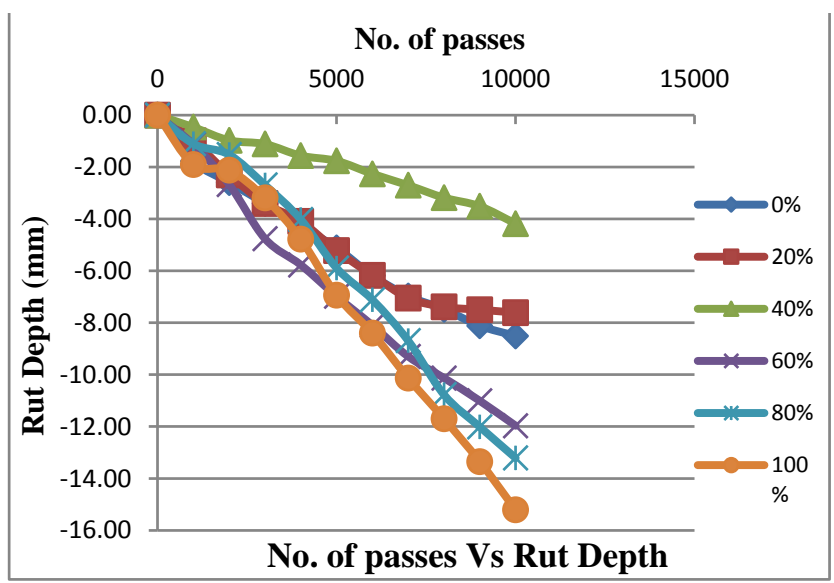

Figure 4: Rutting Performance of the Mixes

\section{CONFLICT OF INTEREST}

The contents of this study are free from plagiarism and therefore the study is original and is not copied from anywhere. Previous work of original authors has also been referenced.

\section{CONCLUSION}

This study concludes that:

- RAP mixtures designed in laboratory using Marshall Method perform the same or even better than the conventional mixture but up to some limit.

- Generally the Marshall stability generally increases linearly as RAP content increases up to 40 percent. The stability of the 40 percent RAP mixtures is even more than that of the stability of conventional mixture.

- Using percentage of RAP above $40 \%$, most of the mixtures did not meet the maximum flow requirements suggesting that the aged bitumen did not participate well and that the mixtures were stressed during loading.

- The use of RAP in design up to $40 \%$ would help to preserve natural resources, reduce price of HMA and improve the performance.

- Also the results of rutting performance shows that RAP contents performs better than the conventional mix but upto a certain limit i.e $40 \%$ RAP content.

- The rut depth of the mixture containing $20 \%$ and $40 \%$ RAP shows rut depth less than that of a virgin mixture which concludes that RAP contents up-to $40 \%$ can perform better than virgin mixture.

- But exceeding RAP content higher than $40 \%$ fails to reach the maximum rut depth of $12 \mathrm{~mm}$ at 10000 passes as per standard which shows the failure of the mixtures containing RAP contents higher than $40 \%$.

\section{RECOMMENDATIONS}

Based on the conclusions of the research the following recommendations are to be considered appropriate.

- It is recommended to construction of a trial section using virgin and RAP blends is suggested to verify the suitability of RAP mixtures to climate conditions and traffic loadings in the country.

- It is recommended for future study, it is recommended that modified binder and $25 \mathrm{~mm}$ NMAS be used to see the performance of the RAP mixtures as the base course material.

\section{ACKNOWLEDGEMENT}

Author is thankful to his supervisors for their consistent help throughout this study. The author is thankful to the Department of Civil Engineering, Sarhad University for providing Lab equipments. 


\section{REFERENCES}

[1] Copeland, Audrey. Reclaimed asphalt pavement in asphalt mixtures: State of the practice. No. FHWA-HRT-11-021. 2011.

[2] Kandhal, Prithvi S., Shridhar S. Rao, and Brad Young. Performance of recycled mixtures in state of Georgia. No. FHWA-GA-94-9209. Georgia. Dept. of Transportation, 1994.

[3] Roberts, Freddy L., et al. "Hot mix asphalt materials, mixture design and construction." (1991).

[4] Sullivan, John. Pavement recycling executive summary and report. Federal Highway Administration, 1996.

[5] Thomas E. Wohlscheid, In-Place Pavement Recycling in New York State, Paper Prepared for the 19th Annual Meeting of the Asphalt Emulsion Manufacturers Association and the 16th Annual Meeting of the Asphalt Recycling \& Reclaiming Association,1992.

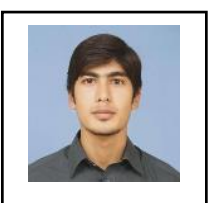

Asif Nawaz, the auther, is resident of Charsadda. $\mathrm{He}$ completed his bachelor degree of Civil Engineering from Sarhad University of Science \& Informtaion Technology, Peshawar in 2016. The auther is pursuing his master's degree in Highway \& Transportaion Enginnering from Sarhad University of Science \& Information Technology, Peshawar. This paper is his research study for the mster's degree. 